\title{
High Temperature and the Ethylene Antagonist 1-Methylcyclopropene Alter Ethylene Evolution Patterns, Antioxidant Responses, and Boll Growth in Gossypium hirsutum
}

\author{
Eduardo M. Kawakami ${ }^{1}$, Derrick M. Oosterhuis ${ }^{2}$, John L. Snider ${ }^{3 *}$, Toby R. FitzSimons ${ }^{2}$ \\ ${ }^{1}$ Av. Antônio Teixeira dos Santos, Rondonópolis, Brazil; ${ }^{2}$ Department of Crop, Soil, and Environmental Sciences, University of Ar- \\ kansas, Fayetteville, USA; ${ }^{3}$ Department of Crop and Soil Sciences, University of Georgia, Tifton, USA. \\ Email: ${ }^{*}$ jlsnider@uga.edu
}

Received April 23 ${ }^{\text {rd }}, 2013$; revised May $24^{\text {th }}, 2013$; accepted June $10^{\text {th }}, 2013$

Copyright (C) 2013 Eduardo M. Kawakami et al. This is an open access article distributed under the Creative Commons Attribution License, which permits unrestricted use, distribution, and reproduction in any medium, provided the original work is properly cited.

\begin{abstract}
The cotton (Gossypium hirsutum L.) crop experiences high temperatures during flowering and boll development, but information regarding the impact of ethylene inhibition and high temperature on early boll development is limited. The objective of this study was to determine the effects of high temperature and the anti-ethylene compound 1-methylcycloprone (1-MCP) on G. hirsutum boll development. Treatments consisted of temperature regime $\left(38 / 20^{\circ} \mathrm{C}\right.$ and $30 /$ $20^{\circ} \mathrm{C}$ ), 1-MCP treatment, and days past anthesis (DPA). High temperature decreased ethylene synthesis by $61 \%$ at 2 DPA, and 1-MCP caused a 40\% decrease in ethylene production at 1 DPA. Glutathione reductase activity increased under high temperature, whereas superoxide dismutase activity (SOD) and membrane peroxidation (malondialdehyde content) remained unchanged. 1-MCP treatment did not affect GR activity in developing bolls. High temperature and 1-MCP treatment increased the weight of cotton bolls collected 8 DPA with an increase of 0.7 and $1 \mathrm{~g}$, respectively. We propose that increased GR activity in bolls exposed to high temperature may mitigate oxidative damage. Additionally, we conclude that ethylene inhibition (either high temperature or 1-MCP-induced) immediately after flowering (1 or 2 DPA) could potentially have positive impacts on early boll growth.
\end{abstract}

Keywords: Ethylene; Glutathione Reductase; Gossypium hirsutum; High Temperature; 1-Methylcyclopropene

\section{Introduction}

Cotton is a major industrial crop grown for fiber, feed and fuel, but yields suffer from extreme sensitivity to stress during reproductive development. Even though cotton originates from warm regions, cotton yields respond negatively to high temperature during the flowering period $[1,2]$ because growing season temperatures often exceed the $30^{\circ} \mathrm{C}$ day temperature optimum for crop growth and development $[2,3]$. The negative effects of high temperature on cotton yield can be attributed to extensive boll abscission [3,4], decreased boll size [2], and decreased number of seeds per boll [2]. The decline in productivity observed for G. hirsutum under high temperature is likely the result of negative impacts on re-

\footnotetext{
"Corresponding author.
}

productive [5-9] and vegetative physiology $[6,10,11]$.

Ethylene is produced by plant tissues during normal developmental processes [12] and under abiotic stress conditions [13]. For example, ethylene is a well-established regulator of leaf senescence [12] and is essential for cotton fiber elongation [14] and boll opening [15]. Under abiotic stress ethylene plays a major role in the regulation of the abscission process in cotton fruits $[16,17]$, where it initiates the formation of the abscission layer in the peduncle that results in fruit shed. Additionally, ethylene is essential for the induction of antioxidant defense systems during abiotic stress [18]. Although ethylene plays a major role in the physiology of heatstressed plants [13], it is not clear in the literature if ethylene increases or decreases under high temperature.

Boll development in $G$. hirsutum occurs in three phases: fiber cell initiation, elongation, and secondary 
wall thickening [19]. The day of anthesis and the first few days following anthesis are critical for proper boll and fiber development in G. hirsutum. Fiber cell initials appear on ovule surfaces on the day of anthesis [20], and assuming successful fertilization, fiber cell elongation continues until approximately 20 days past anthesis (DPA) [19] concomitant with a rapid expansion in boll size [21]. It has been documented that young cotton bolls are especially susceptible to abiotic stress-induced abscission in the first 8 days following anthesis [16]. It was further shown that the gaseous phytohormone ethylene was primarily responsible for this phenomenon [16]. Despite the wealth of information on ethylene's importance in the stress response [22] and the abscission process [12], studies evaluating the effect of ethylene on early boll development and oxidative status under optimal and high temperature conditions are lacking.

1-Methylcyclopropene (1-MCP) is a plant growth regulator that inhibits the action of ethylene by blocking the ethylene receptor sites in the plant cell [23]. Hays et al. [24] evaluated the effect of 1-MCP on a heat-susceptible wheat (Triticum aestivum L.) cultivar and found that 1-MCP enhanced wheat tolerance to high temperature conditions. These authors reported that plants treated with 1-MCP did not exhibit the induction of kernel abortion and reduction in kernel weight as did the untreated plants. Kawakami et al. [25] reported increases in mature boll size in field grown G. hirsutum treated with 1-MCP, but the effect of 1-MCP on early boll development and physiology was not examined. Reports from droughtstressed cotton leaves [26] and heat-stressed soybean leaves and pods [27] have suggested that 1-MCP application increases the activity of ROS scavenging systems under abiotic stress conditions in these tissues. In contrast, under field conditions, Kawakami et al. [25] reported decreased GR activity in 1-MCP-treated G. hirsutum leaves. Similarly, Larkindale and Huang [28] reported that creeping bentgrass leaves treated with an ethylene precursor exhibited enhanced antioxidant enzyme activity and thermotolerance.

Information regarding the impact of ethylene inhibition and high temperature on oxidative stress and early boll development is non-existent for cotton. We hypothesized that heat-stressed cotton reproductive organs would exhibit higher levels of ethylene production and oxidative stress and that application of 1-MCP would lessen ethylene evolution and the magnitude of the stress response. Therefore, the current study was designed with the objective of analyzing the effect of 1-methylcyclopropene and high day temperature on ethylene evolution, antioxidant enzyme response, membrane peroxidation, and reproductive growth in G. hirsutum.

\section{Materials and Methods}

\subsection{Plant Material and Treatments}

The experiment was conducted and repeated at the Altheimer laboratory, Arkansas Agricultural Research and Extension Center in Fayetteville, AR. The cotton (Gossypium hirsutum L.) cultivar "DP444 BG/RR" was planted in 2 liter pots filled with Sunshine potting mix (Sun Gro Horticultural Distribution Inc., Bellevue, WA). The pots were arranged in two large walk-in growth chambers (Model PGW36, Conviron, Winnipeg, Canada) with day/night temperatures of $30 / 20^{\circ} \mathrm{C}, 12$ hour photoperiods, $500 \mu \mathrm{mol} \cdot \mathrm{m}^{-2} \cdot \mathrm{s}^{-1}$ photosynthetically active radiation (PAR), and a relative humidity of $70 \%$. After 6 weeks ( 2 weeks after the pinhead-square stage), the day temperature of one growth chamber was increased in $2^{\circ} \mathrm{C}$ increments every 2 days until the temperature reached $38^{\circ} \mathrm{C}$, the day temperature of the other chamber was maintained at $30^{\circ} \mathrm{C}$. Plants were watered daily with a half-strength Peter's nutrient solution (Spectrum Group, St. Louis, MO). The experiment was arranged in a completely randomized design with three factors and six replications. The factors consisted of temperature $\left(30 / 20^{\circ} \mathrm{C}\right.$ and $38 / 20^{\circ} \mathrm{C}$ ), 1-MCP treatment (treated and untreated), and sample day $(0,1,2,4$ and 8 days after anthesis). The $30^{\circ} \mathrm{C}$ day temperature was chosen because this corresponds to the optimal temperature for cotton growth and development [3], whereas the $38^{\circ} \mathrm{C}$ day temperature was chosen because this is an above-optimal temperature commonly observed under field conditions in many cotton growing regions in the US, and this temperature has been shown to alter reproductive and vegetative physiology in cotton [6].

In the 1-MCP treatment, white flowers (0 days past anthesis; DPA) from the first sympodial position between main-stem nodes 5 to 9 were sprayed using an airbrush (Iwata HP-BCS, Iwata Medea, Portland, OR). Flowers were sprayed at $0900 \mathrm{~h}$ with $0.046 \mathrm{ml}$ of a solution containing $0.053 \mathrm{~g}$ of 1-MCP active ingredient per liter. This dose corresponded approximately to a field application of $10 \mathrm{~g}$ of 1-MCP active ingredient per hectare, with a rate of $187 \mathrm{~L} \cdot \mathrm{ha}^{-1}$. A $0.375 \% \mathrm{v} / \mathrm{v}$ of adjuvant (AF-400, Rohm Hass, Philadelphia, PA) was added to the spray solution. In the control treatment, flowers were sprayed with distilled water + adjuvant.

\subsection{Ethylene and Boll Weight Measurements}

A small, flexible polyethylene chamber (Whirl-Pak; Nasco Atlanta-GA) with a volume of approximately 50 $\mathrm{ml}$ was designed for attachment to flower or bolls for ethylene sampling. Silicon stoppers (Becton Dickinson Vacutainer System 366,430, Franklin Lakes, NJ) with 
dimensions of $16 \times 100 \mathrm{~mm}$ were installed in the end of the flexible chambers to facilitate the air sample collection, where the needle of a $1 \mathrm{ml}$ syringe was inserted through the silicone stopper. To avoid air leaks from the chamber, circular shaped molds of silicone rubber (Dow Corning 3110 RTV, Midland, MI) and a catalyst (Dow Corning 1 Catalyst Standard Cure, Midland, MI) were made to fit around the peduncle and the chambers were closed around the molds and peduncle using plastic cable ties (General Electric Company, Oklahoma City, OK). In addition, a small amount of silicone lubricant (Dow Corning High Vacuum Grease, Midland, MI) was placed around the mold covering the flower peduncles to ensure a tight seal. The flexible chambers were placed on the fruits at $0900 \mathrm{~h}$ and the air samples collected at $1500 \mathrm{~h}(6$ $\mathrm{h}$ period). Air samples of $1 \mathrm{ml}$ were run through a Gas Chromatograph (GC; Varin Chrompack CP-3380, Palo Alto, CA) equipped with a Haysep N 80-100 column for ethylene determination.

To determine the volume of each chamber, immediately after the ethylene sampling was completed, a known amount of ethylene was injected into each chamber. About 5 minutes after the ethylene fortification, another sample of air from each chamber was collected and passed through the GC. Chamber volume was calculated according to the following equation: Chamber volume $(\mathrm{ml})=[$ Volume of Ethylene Injected $(\mu \mathrm{L}) \times 1000] \div$ [Ethylene last sampling $\left(\mu \mathrm{L} \cdot \mathrm{L}^{-1}\right)$ - Ethylene first sampling $\left.\left(\mu \mathrm{L} \cdot \mathrm{L}^{-1}\right)\right]$.

After the ethylene sampling, each fruit was excised and fresh weight (FW) determined. Calculations of ethylene production were expressed as $\mu \mathrm{l} \cdot \mathrm{g}^{-1} \cdot \mathrm{FW} \cdot \mathrm{h}^{-1}$. Flowers were kept at $-80^{\circ} \mathrm{C}$ for subsequent enzyme extraction. In addition, the fresh weight measurements (in g) were used to monitor developmental changes in boll growth.

\subsection{Soluble Protein Extraction}

Soluble proteins were extracted from ovaries and young bolls according to the methods of Gomez et al. [29], with modification. G. hirsutum ovaries and bolls collected at 0 , 1 and 2 days past anthesis, were selected for soluble protein extraction, whereas soluble protein extraction was not conducted on bolls at 4 and 8 days past anthesis due to the presence of seeds.

Ovaries and young bolls were homogenized with a mortar and pestle on ice in a 4 to 1 ratio of extraction buffer solution to g FW. The extraction solution was comprised of $50 \mathrm{mM}$ piperazinediethanesulfonic acid (PIPES) buffer (pH 6.8), $6 \mathrm{mM}$ cysteine hydrochloride, $10 \mathrm{mM}$ D-isoascorbate, $1 \mathrm{mM}$ ethylenediaminetetraacetic acid (EDTA), $0.3 \%$ Triton X-100, and 1\% (w/v) soluble polyvinylpyrrolidone (PVP). Solutions were further blended for $1 \mathrm{~min}$ in a tube containing $0.2 \mathrm{~g}$ insoluble
PVP and 1 drop of antifoam A emulsion using a homogenizer (Model Polytron; Brinkman Instruments Inc., Palo Alto, CA). Samples were centrifuged at 21,000 $\times g$ for $20 \mathrm{~min}\left(4^{\circ} \mathrm{C}\right)$, and the supernatants were utilized for determination of antioxidant enzyme activity and malondialdehyde (MDA) content.

\subsection{Glutatione Reductase}

The glutathione reductase (GR) assay of Schaedle and Bassham [30] was followed. The assay was initiated by placing $950 \mu \mathrm{l}$ of a reaction solution and $50 \mu \mathrm{l}$ of sample extract in a $1 \mathrm{~mL}$ quartz cuvette. GR activity was measured according to the oxidation of NADPH $+\mathrm{H}$ with a Biospec 1601 UV/VIS spectrophotometer (Shimadzu, Columbia, Maryland). The instrument measured absorbance at $340 \mathrm{~nm}$ and measurements were made in $2 \mathrm{~s}$ intervals during a $1 \mathrm{~min}$ measurement period. GR activities were expressed as Units $\cdot \mathrm{g}^{-1} \cdot \mathrm{FW}$.

\subsection{Superoxide Dismutase}

Superoxide dismutase activity of enzyme extracts was quantified by a modification of the method of $\mathrm{Lu}$ and Foo [31]. Briefly, two $17 \mu \mathrm{l}$ aliquots of enzyme extract from each sample were added to two wells of a 96 well microplate containing $161.5 \mu \mathrm{l}$ reaction solution comprised of $0.4 \mathrm{mM}$ xanthine and $0.24 \mathrm{mM}$ nitro blue tetrazolium chloride (NBT) in $0.1 \mathrm{M}$ phosphate buffer (pH 8.0). Subsequently, $161.5 \mu 1$ of xanthine oxidase (EC 1.17.3.2; 0.049 units $\cdot \mathrm{ml}^{-1}$ ) diluted in $0.1 \mathrm{M}$ phosphate buffer ( $\mathrm{pH}$ 8.0) was added to one well containing a sample and a blank was prepared by adding $161.5 \mu \mathrm{l}$ of 0.1 $\mathrm{M}$ phosphate buffer $(\mathrm{pH}=8.0)$ to the other well containing an aliquot of the same sample. Aqueous SOD standards $\left(0,5,10,25\right.$, and 50 units $\left.\cdot \mathrm{ml}^{-1}\right)$ were prepared and $17 \mu \mathrm{l}$ of each standard was mixed with reaction solution followed by the addition of xanthine oxidase as described above. The resulting mixtures were maintained at $37^{\circ} \mathrm{C}$ for $20 \mathrm{~min}$, and the absorbance of NBT was measured at $560 \mathrm{~nm}$ using a microplate reader. SOD activity was determined by subtracting the $\mathrm{A}_{560}$ of the sample in the absence of xanthine oxidase from the $A_{560}$ of the sample in the presence of xanthine oxidase and comparing with the SOD standard curve. SOD activity was expressed as SOD units $\cdot \mathrm{g}^{-1} \cdot \mathrm{FW}$.

\subsection{Malondialdehyde (MDA)}

Membrane peroxidation was measured with a modification of the method of Heath and Packer [32]. A $1 \mathrm{ml}$ solution of enzyme extract was mixed with a $4 \mathrm{ml}$ solution of $20 \%$ TCA containing $0.5 \%$ TBA. The mixture was incubated at $95^{\circ} \mathrm{C}$ for $30 \mathrm{~min}$ and then quickly cooled in an ice-bath. After centrifugation at $14,000 \mathrm{rpm}$ for $10 \mathrm{~min}$ 
the absorbance of the supernatant was measured at 532 $\mathrm{nm}$ and $600 \mathrm{~nm}$. The MDA concentration was calculated according to the following equation: MDA equivalents $\left(\mathrm{nmol} \cdot \mathrm{ml}^{-1}\right)=\left[\left(\mathrm{A}_{532}-\mathrm{A}_{600}\right) / 155,000\right] 10^{6}$ where $\mathrm{A}_{532}$ and $\mathrm{A}_{600}$ are the absorbances at 532 and $600 \mathrm{~nm}$, respectively. Total MDA content was expressed as $\mathrm{nmol} \cdot \mathrm{g}^{-1} \cdot \mathrm{FW}$.

\subsection{Statistical Analyses}

A three factor full factorial analysis of variance was utilized to evaluate the effects of temperature, 1-MCP treatment, and days past anthesis on ethylene production, oxidative status, and boll growth in G. hirsutum, and conventional LSD $(\alpha=0.05)$ post hoc analysis was used to identify statistical differences between means. The software JMP 7 (SAS Institute Cary, NC) was used to perform all statistical analyses. Means and standard errors were assembled into graphs using the Sigma Plot software version 10 (Systat Software, Inc., San Jose, CA).

\section{Results}

\subsection{Ethylene production}

Figure 1 shows the stages of development at which ethylene sampling was conducted. 0 DPA represents the day of anthesis and the day that 1-mcp was applied (Figure 1(a)). The typical pattern of post-anthesis boll development is also shown in cotton, where the petals turn pink following anthesis (1-DPA; Figure 1(b)) and floral components (petals, staminal column, and style) senesce and abscise from the ovary (2-4 DPA; Figure 1(c), (d)), and rapid boll expansion continues (8 DPA; Figure 1(e)). Statistical analysis of ethylene evolution data indicated that there was no significant three-way interaction effect between 1-MCP treatment, days past anthesis (DPA), and temperature $(P=0.3560)$. However, the model showed a significant interaction between temperature and DPA $(P$ $<0.0001)$ and between 1-MCP treatment and DPA $(P=$ $0.0013)$. Since there was a two-way interaction between the aforementioned variables, the interactions 1-MCP treatment $\times$ DPA and temperature treatment $\times$ DPA were analyzed separately utilizing LSD post hoc analysis.

High day temperature (Figure 2(a)) resulted in significantly lower ethylene evolution levels at 1 and 2 DPA relative to the optimal day temperature regime. For example, at day 1 and 2 , fruits at $38 / 20^{\circ} \mathrm{C}$ had, respectively, a $25 \%$ and $61 \%$ decrease in ethylene production compared to fruits at $30 / 20^{\circ} \mathrm{C}$. Ethylene evolution rates were not significantly affected by temperature treatment at 0,4 , and 8 DPA, however, at day 8 , values of ethylene measurements collected at $38^{\circ} \mathrm{C}\left(0.351 \pm 0.055 \mathrm{nl} \cdot \mathrm{g}^{-1} \cdot \mathrm{FW}\right)$ exhibited a numeric increase ( 2.4 fold) when compared to $30^{\circ} \mathrm{C}\left(0.146 \pm 0.021 \mathrm{nl} \cdot \mathrm{g}^{-1} \cdot \mathrm{FW}\right)$. Ethylene production declined with successive increases in DPA under high temperature; however, ethylene production by bolls exposed to optimal temperature did not exhibit a decline until 4 DPA (Figure 2(a)).

The 1-MCP treatment (Figure 2(b)) only affected ethylene evolution at 1 DPA; ethylene production was unaffected by 1 -MCP treatment at $0,2,4$, and 8 days. At 1 DPA, compared to the untreated control, 1-MCP treated bolls exhibited a $40 \%$ decrease in ethylene evolution rates (Figure 2(b)). However, at 2 days after 1-MCP application, there were no significant differences between 1-MCP treated and untreated control treatments. Thereafter, ethylene concentration declined in both treatments to low levels at day 8 .

\subsection{Antioxidant Enzyme Activity and Malondialdehyde (MDA) Content}

Measurement of GR activity indicated no significant three-way interaction $(P=0.1977)$; only a two-way interaction between temperature and DPA was detected (Figure 3(a); $P=0.0219)$. Due to the presence of high variability, the 1 -MCP treatment $(P=0.9469)$ effect and the interaction between 1-MCP treatment and DPA $(P=$ 0.4027) was not significant (Figure 3(b)). Regarding the interaction between temperature and DPA, GR activity

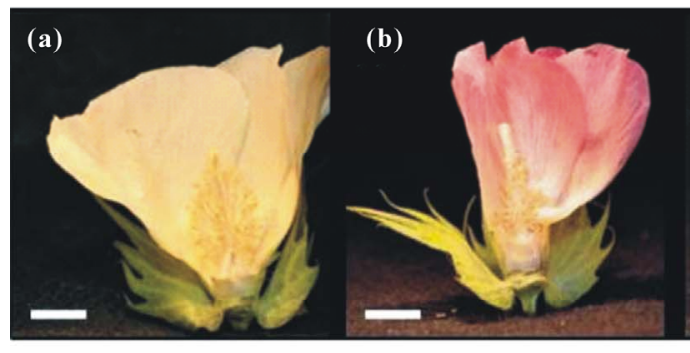

0

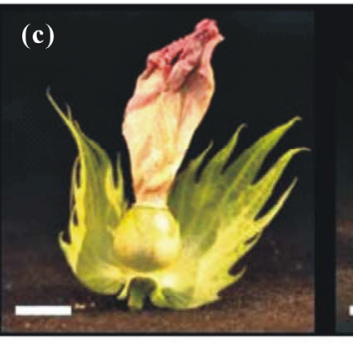

2 (d)
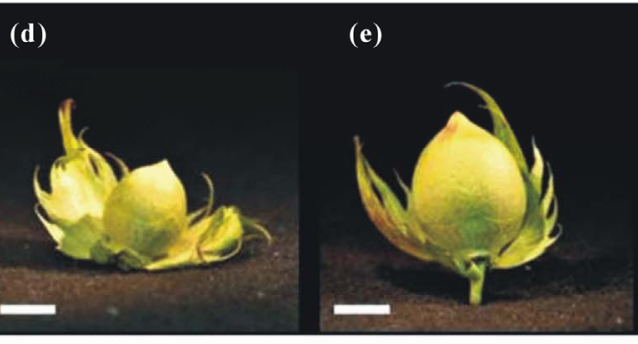

4
8

Days Past Anthesis

Figure 1. Gossypium hirsutum flowers and developing bolls at 0 (a), 1 (b), 2 (c), 4 (d), and 8 (e) days past anthesis (Scale bar $=$ $1 \mathrm{~cm})$. 


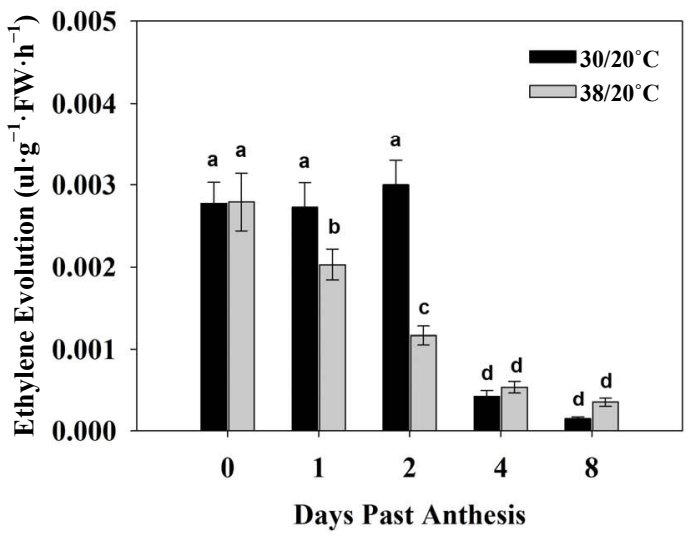

(a)

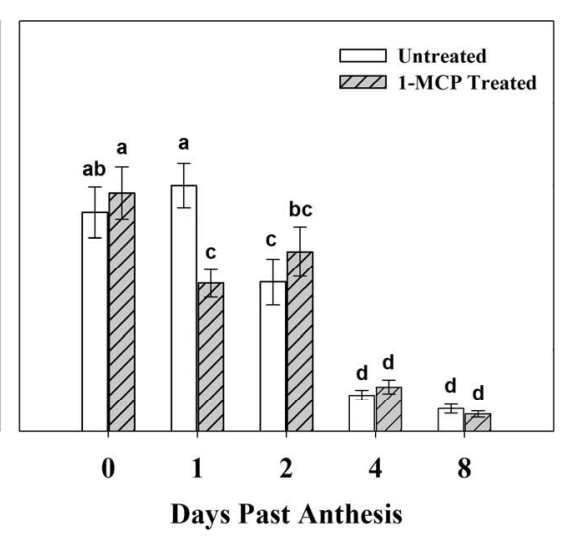

(b)

Figure 2. Growth temperature (a) and 1-MCP (b) effects on ethylene evolution patterns for Gossypium hirsutum flowers and developing bolls at $0,1,2,4$, and 8 days past anthesis. Values are means \pm standard errors $(n=24)$, and values not sharing a common letter are significantly different (LSD; $P<0.05)$. In (a), data were pooled across both 1 -MCP treatments $(1-M C P$ treated and untreated plants) for each growth temperature regime, and in (b) data were pooled across both temperature regimes $\left(30 / 20^{\circ} \mathrm{C}\right.$ and $38 / 20^{\circ} \mathrm{C}$ day/night temperatures).

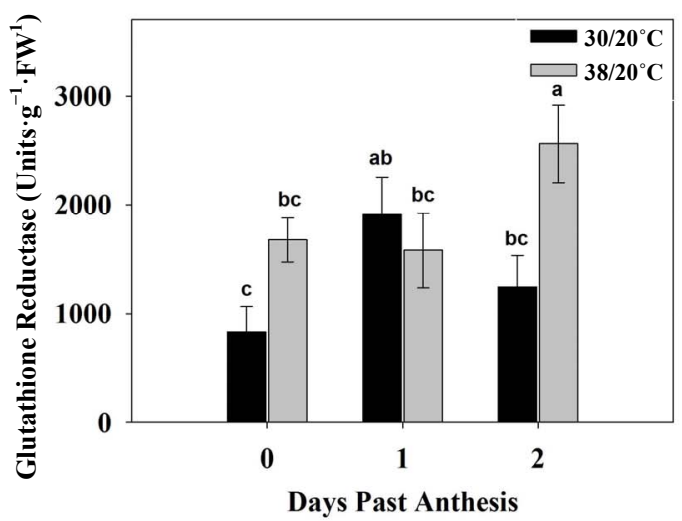

(a)

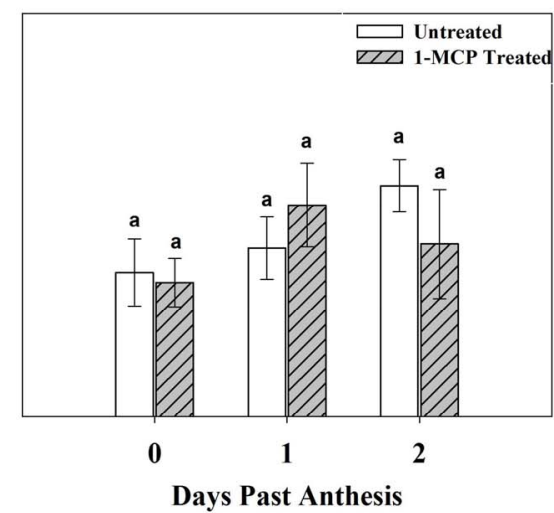

(b)

Figure 3. Growth temperature (a) and 1-MCP (b) effects on glutathione reductase activity in Gossypium hirsutum flowers and developing bolls at 0,1 , and 2 days past anthesis. Values are means \pm standard errors $(n=10)$, and values not sharing a common letter are significantly different (LSD; $P<0.05)$. In (a), data were pooled across both 1 -MCP treatments $(1-M C P$ treated and untreated plants) for each growth temperature regime, and in (b) data were pooled across both temperature regimes $\left(30 / 20^{\circ} \mathrm{C}\right.$ and $38 / 20^{\circ} \mathrm{C}$ day $/$ night temperatures).

was unaffected by temperature treatment at 0 and 1 DPA, but significantly higher GR activity was observed in high temperature treated bolls at 2 DPA, in comparison with bolls grown under optimal temperature conditions (Figure 3(a)). The malondialdehyde (MDA) content and superoxide dismutase (SOD) activity of ovaries and young bolls collected from 0-3 DPA was not affected by 1-MCP or temperature treatments (Tables $\mathbf{1}$ and $\mathbf{2}$ ).

\subsection{Boll Weight}

There was no significant three-way interaction effect between 1-MCP treatment, DPA, and temperature, but there were significant two-way interactions between 1 -MCP treatment $\times$ DPA $(P=0.008)$ and temperature $\times$
DPA $(P=0.028)$. Therefore, these interactions were analyzed separately utilizing LSD post hoc analysis. High temperature caused a significant increase in boll weight 8 days after application (Figure 4(a)) Similarly, $1-\mathrm{MCP}$ also significantly increased the weight of cotton bolls at day 8 (Figure 4(b)), where 1-MCP treated bolls averaged a gain of $1 \mathrm{~g}$ in comparison to untreated bolls. Neither temperature treatment nor 1-MCP treatment had a significant effect on boll weight at $0,1,2$, and 4 DPA (Figure 4).

\section{Discussion}

In contrast with our hypothesis, we observed decreased ethylene evolution with high temperature (Figure 2). 


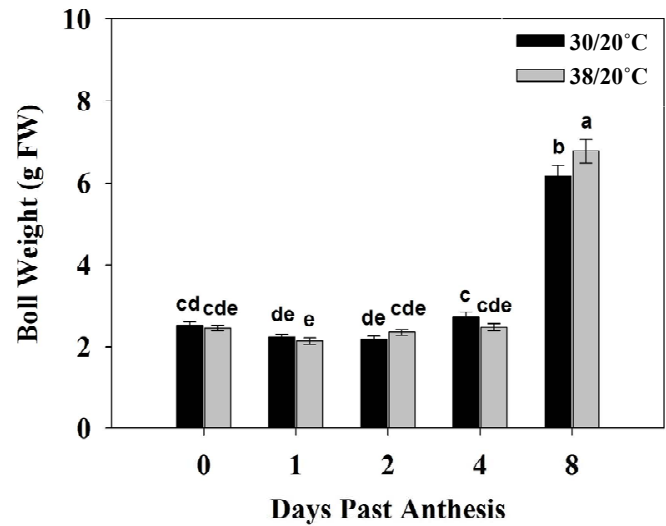

(a)

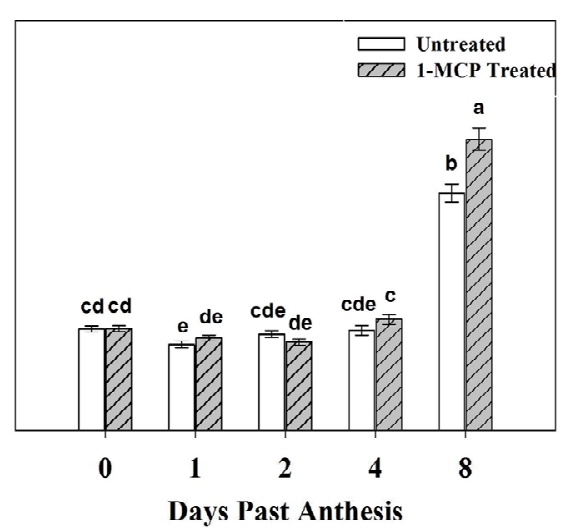

(b)

Figure 4. Growth temperature (a) and 1-MCP (b) effects on boll size for Gossypium hirsutum at 0, 1, 2, 4, and 8 days past anthesis. At stages where floral tissue was present, the ovary was excised from the surrounding tissue and weighed to obtain a "boll" weight. Values are means \pm standard errors $(n=24)$, and values not sharing a common letter are significantly different (LSD; $P<0.05)$. In (a), data were pooled across both 1-MCP treatments (1-MCP treated and untreated plants) for each growth temperature regime, and in (b) data were pooled across both temperature regimes $\left(30 / 20^{\circ} \mathrm{C}\right.$ and $38 / 20^{\circ} \mathrm{C}$ day/night temperatures).

Table 1. Effect of 1-MCP treatment on SOD and MDA content of cotton ovaries and young bolls collected from 0-2 DPA. Values are means \pm standard error $(n=11)$; values sharing a common letter within a column are not significantly different $(P>0.05)$.

\begin{tabular}{ccc}
\hline \multirow{2}{*}{ Treatments } & SOD & MDA \\
\cline { 2 - 3 } & Units $\cdot \mathrm{g}^{-1} \cdot \mathrm{FW}$ & $\mathrm{nmol} \cdot \mathrm{g}^{-1} \cdot \mathrm{FW}$ \\
\hline Untreated Control & $64.67 \pm 9.76^{\mathrm{a}}$ & $5.54 \pm 0.33^{\mathrm{a}}$ \\
1-MCP Treated & $64.33 \pm 18.88^{\mathrm{a}}$ & $5.12 \pm 0.32^{\mathrm{a}}$ \\
\hline
\end{tabular}

Table 2. Effect of temperature on SOD and MDA content of cotton ovaries and young bolls collected from 0-2 DPA. Values are means \pm standard error $(n=11)$; values sharing a common letter within a column are not significantly different $(P>0.05)$.

\begin{tabular}{ccc}
\hline \multirow{2}{*}{ Treatments } & SOD & MDA \\
\cline { 2 - 3 } & ${\text { Units } \cdot \mathrm{g}^{-1} \cdot \mathrm{FW}}$ & $\mathrm{nmol} \cdot \mathrm{g}^{-1} \cdot \mathrm{FW}$ \\
\hline $30 / 20^{\circ} \mathrm{C}$ (Day/Night) & $57.80 \pm 8.46^{\mathrm{a}}$ & $5.09 \pm 0.31^{\mathrm{a}}$ \\
$38 / 20^{\circ} \mathrm{C}$ (Day/Night) & $71.17 \pm 20.62^{\mathrm{a}}$ & $5.62 \pm 0.34^{\mathrm{a}}$ \\
\hline
\end{tabular}

Although some authors have observed increases in ethylene production under high temperature stress [24], findings similar to those of the present study were also observed by Field [33] in leaf discs of Phaseolus vulgaris L., and by Saltveit and Dilley [34] in stem sections of etiolated Pisum sativum L. These authors attributed decreased ethylene synthesis under high temperature to disturbance of cell membrane integrity. In the present study membrane damage, as measured by MDA estimation of lipid peroxidation, was not observed under high temperature (Table 1). However, perturbations in membrane function cannot be ruled out because increases in membrane permeability [10] and fluidity [35] are wellknown leaf responses to high temperature but were not quantified in the present study.

Additionally, it has been reported that high temperature increases abscisic acid (ABA) content in maize kernels [36], and it is well-documented that ABA accumulation under drought stress is inhibitory to ethylene production [37,38]. It is, therefore, interesting to speculate that heat stress may inhibit ethylene production in developing $G$. hirsutum bolls by an ABA-modulated mechanism similar to that observed under drought stress conditions. In this study we also do not have data regarding receptor sensitivity under high temperature; however, receptor sensitivity to ethylene is also a major factor governing autocatalytic ethylene production [39]. Consequently, high temperature could potentially limit ethylene production under high temperature by limiting receptor sensitivity to the hormone.

The mechanism whereby 1-MCP inhibits the physiological action of ethylene is well-established. 1-MCP binds to ethylene receptors with $10 \times$ the affinity of ethylene, thereby preventing ethylene binding and the subsequent plant response to ethylene (i.e. the plant tissue is rendered insensitive to ethylene) [23,40]. 1-MCP-induced ethylene insensitivity lasts approximately $4 \mathrm{~d}$ after application [23]. However, the effect of 1-MCP on ethylene production is not clear. Blankenship and Dole [23] reported that 1-MCP reduced ethylene synthesis in strawberry, apples, avocado, plum, apricot, kiwifruit, pears, citrus leaves, citrus explants, carnation and moth orchid flowers. Whereas, Selvarajah et al. [41] reported that 
1-MCP caused an increase in ethylene production in pineapple (Ananas comosus). In addition, grapefruit (Citrus paradise) infected by Penicillium digitarium and coriander flowers (Coriandrum sativum) treated with 1-MCP exhibited higher ethylene synthesis $[42,43]$. An experiment with bananas (Musa $\mathrm{sp}$ ) also showed higher ethylene production with 1-MCP treatment [44].

In tomato, 1-MCP has been shown to inhibit ethylene production by preventing the accumulation of the ethylene biosynthetic enzymes 1-aminocyclopropane-1-carboxylate (ACC) oxidase and ACC synthase and their associated mRNA transcripts (Reviewed in Blankenship and Dole [23]). This indicated strong positive feedback regulation for ethylene synthesis when 1-MCP is applied. Our experiment showed that 1-MCP changed the ethylene production pattern of cotton reproductive organs, resulting in decreased ethylene production 1 day after 1-MCP application (Figure 2(b)). It is possible that 1-MCP decreased ethylene by affecting the production of ACC synthase and ACC oxidase, the enzymes responsible for converting S-adenosyl-methionine into ethylene.

High temperature stress caused a significant increase in GR activity at two DPA (Figure 3) but SOD was unaffected by either temperature or 1-MCP treatment (Tables 1 and 2). Snider et al. [6,8] have also reported increases in GR activity in G. hirsutum pistils exposed to high temperature conditions. Importantly, GR activity increased in young bolls (Figure 3) exposed to high temperature, but this increase does not appear to be associated with increased ethylene production, since ethylene production was decreased by high temperature (Figure 2). Additionally, MDA concentrations were not altered by high temperature treatment (Tables 1 and 2), suggesting that elevated GR activity is an important means of protecting the developing boll from oxidative damage during high temperature exposure. Reports from droughtstressed cotton leaves [26] and heat-stressed soybean leaves and pods [27] have suggested that 1-MCP application increases the activity of ROS scavenging systems under abiotic stress conditions in these tissues. In contrast, under field conditions, Kawakami et al. [25] reported decreased GR activity in 1-MCP-treated G. hirsutum leaves. Similarly, Larkindale and Huang [28] reported that creeping bentgrass leaves treated with an ethylene precursor exhibited enhanced antioxidant enzyme activity and thermotolerance. Our results showed that 1-MCP did not significantly affect GR activity (Figure 3), which may have been due to the high level of withintreatment variability.

An interesting finding of the current study is that high temperature treatment and 1-MCP application both resulted in lower levels of ethylene evolution in the initial days (1-2 DPA) following anthesis (0 DPA; Figure 2) and an increase in boll size at 8 DPA (Figure 4). These findings suggest that lower ethylene production during the initial days following anthesis may positively affect boll size at later stages. 1-MCP is well-known to limit receptor sensitivity for $\sim 4 \mathrm{~d}$ following application, and may be the cause of lower ethylene production during the early stages post-anthesis. Because boll size was recorded on a fresh weight basis in the current study, it is unclear whether or not boll size increases were the result of greater carbon allocation to reproductive sinks or increases in cell expansion without concomitant changes in dry matter accumulation. Although ethylene has been shown to promote fiber cell expansion during the elongation phase [14], information regarding regulation of fiber cell initiation is limited [19]. Therefore, it is possible that lower ethylene concentrations or receptor sensitivity to ethylene during the early stages of fiber cell development could promote fiber cell initiation, which would later manifest itself as an increase in boll size during the fiber elongation phase (8 DPA; Figure 4)).

Although we anticipated negative effects of high temperature on young boll growth, this trend was not observed. At 8 DPA, young cotton bolls exposed to high temperature were significantly larger than those grown under control conditions (Figure 4). In contrast, a number of studies have reported decreased mature boll size under high temperature exposure $[2,45]$, possibly due to poor seed set [2] as a consequence of decreased fertilization efficiency [6]. The present study is the first to report heat-induced increases in size for young, expanding bolls. Our findings suggest that heat-induced declines in mature boll size reported previously by other authors do not result from negative impacts on early boll growth. Our findings show that high temperature limits ethylene production immediately following anthesis and increases young boll size. However, ethylene inhibition should not be considered the primary reason for increased boll size under high temperature because heat stress causes a myriad of biochemical and physiological perturbations that could not be accounted for in the present study.

\section{Conclusion}

In conclusion, high temperature and 1-MCP changed the pattern of ethylene production of cotton reproductive organs; a decrease in ethylene synthesis was observed in the 1-MCP treatment 1 day after application and in the high temperature 2 days after anthesis. In addition, high temperature and 1-MCP treatment caused an increase in the fresh weight of cotton bolls collected 8 days after anthesis. It is also suggested that ethylene inhibition during the early stages of fiber development may influence boll size at later stages in development, possibly by positively impacting the fiber initiation process. Because GR 
activity increased under high temperature without concomitant increases in MDA content or ethylene evolution it is suggested that elevated GR activity in young bolls exposed to high temperature is an important mechanism for preventing oxidative damage. Additionally, increases in GR activity in developing bolls under high temperature are not associated with increased ethylene evolution.

\section{Acknowledgements}

The authors thank the University of Arkansas Agricultural Experiment Station and Agrofresh Inc. for supporting this research.

\section{REFERENCES}

[1] D. M. Oosterhuis, "Day or Night High Temperatures: A Major Cause of Yield Variability," Cotton Grower, Vol. 46, 2002, pp. 8-9.

[2] W. T. Pettigrew, "The Effect of Higher Temperatures on Cotton Lint Yield Production and Fiber Quality," Crop Science, Vol. 48, No. 1, 2008, pp. 278-285. doi:10.2135/cropsci2007.05.0261

[3] K. R. Reddy, H. F. Hodges and V. R. Reddy, "Temperature Effects on Cotton Fruit Retention," Agronomy Journal, Vol. 84, No. 1, 1992, pp. 26-30. doi:10.2134/agronj1992.00021962008400010006x

[4] D. Zhao, K. R. Reddy, V. G. Kakani, S. Koti and W. Gao, "Physiological Causes of Cotton Fruit Abscission under Conditions of High Temperature and Enhanced Ultraviolet-B Radiation," Physiologia Plant, Vol. 124, No. 2, 2005, pp. 189-199. doi:10.1111/j.1399-3054.2005.00491.x

[5] J. J. Burke, J. Velten and M. J. Oliver, "In Vitro Analysis of Cotton Pollen Germination," Agronomy Journal, Vol. 96, No. 2, 2004, pp. 359-368. doi:10.2134/agronj2004.0359

[6] J. L. Snider, D. M. Oosterhuis, B. W. Skulman and E. M. Kawakami, "Heat Stress-Induced Limitations to Reproductive Success in Gossypium hirsutum," Physiologia Plant, Vol. 137, No. 2, 2009, pp. 125-138. doi:10.1111/j.1399-3054.2009.01266.x

[7] J. L. Snider, D. M. Oosterhuis and E. M. Kawakami, "Diurnal Pollen Tube Growth Rate Is Slowed by High Temperature in Field-Grown Gossypium hirsutum Pistils," Journal of Plant Physiology, Vol. 168, No. 5, 2011, pp. 441-448. doi:10.1016/j.jplph.2010.08.003

[8] J. L. Snider, D. M. Oosterhuis and E. M. Kawakami, "Mechanisms of Reproductive Thermotolerance in Gossypium hirsutum: The Effect of Genotype and Exogenous Calcium Application," Journal of Agronomy and Crop Science, Vol. 197, No. 3, 2011, pp. 228-236. doi:10.1111/j.1439-037X.2010.00457.x

[9] J. L. Snider, D. M. Oosterhuis, D. A. Loka and E. M. Kawakami, "High Temperature Limits in Vivo Pollen Tube Growth Rates by Altering Diurnal Carbohydrate Balance in Field-Grown Gossypium hirsutum Pistils,"
Journal of Plant Physiology, Vol. 168, No. 11, 2011, pp. 1168-1175. doi:10.1016/j.jplph.2010.12.011

[10] S. M. Schrader, R. R. Wise, W. F. Wacholtz, D. R. Ort and T. D. Sharkey, "Thylakoid Membrane Responses to Moderately High Leaf Temperature in Pima Cotton," Plant, Cell \& Environment, Vol. 27, No. 6, 2004, pp. 725-735. doi:10.1111/j.1365-3040.2004.01172.x

[11] J. L. Snider, D. M. Oosterhuis and E. M. Kawakami, "Genotypic Differences in Thermotolerance Are Dependent upon Pre-Stress Capacity for Antioxidant Protection of the Photosynthetic Apparatus in Gossypium hirsutum," Physiologia Plant, Vol. 138, No. 3, 2010, pp. 268-277. doi:10.1111/j.1399-3054.2009.01325.x

[12] K. M. Brown, "Ethylene and Abscission," Physiologia Plant, Vol. 100, No. 3, 1997, pp. 567-576. doi:10.1111/j.1399-3054.1997.tb03062.x

[13] F. B. Abeles, P. W. Morgan and M. E. Saltveit Jr., "Ethylene in Plant Biology," 2nd Editon, San Diego, Academic, 1992.

[14] Y. H. Shi, S. W. Zhu, X. Z. Mao, J. X. Feng, Y. M. Qin, L. Zhang, J. Cheng, L. P. Wei, Z. Y. Wang and Y. X. Zhu, "Transcriptome Profiling, Molecular Biological, and Physiological Studies Reveal a Major Role for Ethylene in Cotton Fiber Elongation," Plant Cell, Vol. 18, No. 3, 2006, pp. 651-664. doi:10.1105/tpc.105.040303

[15] A. M. Stewart, K. L. Edmisten and R. Wells, "Boll Openers in Cotton: Effectiveness and Environmental Influences," Field Crops Research, Vol. 67, No. 1, 2000, pp. 83-90. doi:10.1016/S0378-4290(00)00093-9

[16] G. Guinn, "Fruit Age and Changes in Abscisic Acid Content, Ethylene Production, and Abscission Rate of Cotton Fruits," Plant Physiology, Vol. 69, No. 2, 1982, pp. 349-352. doi:10.1104/pp.69.2.349

[17] J. A. Lipe and P. W. Morgan, "Ethylene: Role in Fruit Abscission and Dehiscence Process," Plant Physiology, Vol. 50, No. 6, 1972, pp. 759-764. doi:10.1104/pp.50.6.759

[18] J. G. Scandalios, "Oxygen Stress and Superoxide Dismutases," Plant Physiology, Vol. 101, No. 1, 1992, pp. 7-12.

[19] J. J. Lee, A. W. Woodward and Z. J. Chen, "Gene Expression and Early Events in Cotton Fibre Development," Annals of Botany, Vol. 100, No. 7, 2007, pp. 1391-1401. doi:10.1093/aob/mcm232

[20] J. M. D. Stewart, "Integrated Events in the Flower and Fruit,” In: J. R. Mauney and J. M. D. Stewart, Ed., Cotton Physiology, The Cotton Foundation, Memphis, 1986, pp. 261-300.

[21] A. M. Schubert, C. R. Benedict and R. J. Kohel, "Carbohydrate Distribution in Bolls," In: J. R. Mauney and J. M. D. Stewart, Ed., Cotton Physiology, The Cotton Foundation, Memphis, 1986, pp. 311-324.

[22] A. B. Bleecker and H. Kende, "Ethylene: A Gaseous Signal Molecule in Plants," Annual Review of Cell and Developmental Biology, Vol. 16, 2000, pp. 1-18. doi:10.1146/annurev.cellbio.16.1.1

[23] S. M. Blankenship and J. M. Dole, "1-Methylcyclopropene: A Review," Postharvest Biology and Technology, 
Vol. 28, No. 1, 2003, pp. 1-25. doi:10.1016/S0925-5214(02)00246-6

[24] D. B. Hays, J. H. Do, R. E. Manson, G. Morgan and S. A. Finlayson, "Heat Stress Induced Ethylene Production in Developing Wheat Grains Induces Kernel Abortion and Increase Maturation in Susceptible Cultivar," Plant Science, Vol. 172, No. 3, 2007, pp. 1113-1123. doi:10.1016/i.plantsci.2007.03.004

[25] E. M. Kawakami, D. M. Oosterhuis and J. L. Snider, "1-Methylcyclopropene Effects on the Physiology and Yield of Field-Grown Cotton," Journal of Cotton Science, Vol. 14, 2010, pp. 233-239.

[26] E. M. Kawakami, D. M. Oosterhuis and J. L. Snider, "Physiological Effects of 1-Methylcyclopropene on WellWatered and Water-Stressed Cotton Plants," Journal of Plant Growth Regulation, Vol. 29, No. 3, 2010, pp. 280288. doi:10.1007/s00344-009-9134-3

[27] M. Djanaguiraman and P. V. V. Prasad, "Ethylene Production under High Temperature Stress Causes Premature Leaf Senescence in Soybean," Functional Plant Biology, Vol. 37, No. 11, 2010, pp. 1071-1084 doi:10.1071/FP10089

[28] J. Larkindale and B. Huang, "Thermotolerance and Antioxidant Systems in Agrostis stolonifera: Involvement of Salicylic Acid, Abscisic Acid, Calcium, Hydrogen Peroxide, and Ethylene," Journal of Plant Physiology, Vol. 161, No. 4, 2004, pp. 405-413. doi:10.1078/0176-1617-01239

[29] S. K. Gomez, D. M. Oosterhuis, S. N. Rajguru and D. R. Johnson, "Foliar Antioxidant Enzyme Responses in Cotton after Aphid Herbivory," Journal of Cotton Science, Vol. 8, 2004, pp. 99-104.

[30] M. Schaedle and J. A. Bassham, "Chloroplast Glutathione Reductase (in Spinach)," Plant Physiology, Vol. 59, No. 5, 1977, pp. 1011-1012. doi:10.1104/pp.59.5.1011

[31] Y. Lu and L. Y. Foo, "Antioxidant Activities of Polyphenols from Sage (Salvia officinalis)," Food Chemistry, Vol. 75, No. 2, 2001, pp. 197-202. doi:10.1016/S0308-8146(01)00198-4

[32] R. L. Heath and L. Packer, "Photoperoxidation in Isolated Chloroplasts. I. Kinetics and Stoichiometry of Fatty Acid Peroxidation," Archives of Biochemistry and Biophysics, Vol. 125, 1968, pp. 180-198.

[33] R. J. Field, “A Relationship between Membrane Permeability and Ethylene Production at High Temperature in Leaf Tissue of Phaseoulus vulgaris L.," Annals of Botany, Vol. 48, 1981, pp. 33-39.

[34] M. E. Saltveit Jr. and D. R. Dilley, "Rapidly Induced Wound Ethylene from Excised Segments of Etiolated Pisum sativum L., cv. Alaska," Plant Physiology, Vol. 61, No. 4, 1978, pp. 675-679. doi:10.1104/pp.61.4.675
[35] N. Murata and D. A. Los, "Membrane Fluidity and Temperature Perception," Plant Physiology, Vol. 115, 1997, pp. 875-879.

[36] N. Cheikh and R. J. Jones, "Disruption of Maize Kernel Growth and Development by Heat Stress," Role of Cytokinin/Abscisic Acid Balance," Plant Physiology, Vol. 106, 1994, pp. 45-51.

[37] R. E. Sharp, "Interaction with Ethylene: Changing Views on the Role of Abscisic Acid in Roots and Shoot Growth Responses to Water Stress," Plant, Cell \& Environment, Vol. 25, No. 2, 2002, pp. 211-222. doi:10.1046/j.1365-3040.2002.00798.x

[38] R. Pierik, R. Sasidharan and L. A. C. Voesenek, "Growth Control by Ethylene: Adjusting Phenotypes to the Environment," Journal of Plant Growth Regulation, Vol. 26, No. 2, 2007, pp. 188-200. doi:10.1007/s00344-006-0124-4

[39] H. Klee and D. Tieman, "The Tomato Ethylene Receptor Gene Family: Form and Function," Plant Physiology, Vol. 115 , No. 3, 2002, pp. 336-341. doi:10.1034/j.1399-3054.2002.1150302.x

[40] B. M. Binder and A. B. Bleecker, "A Model for Ethylene Receptor Function and 1-Methylcyclopropene Action," Acta Horticulturae, Vol. 628, 2003, pp. 177-187.

[41] S. Selvarajah, A. D. Bauchot and P. J. John, "Internal Browning in Cold-Stored Pineapples Is Suppressed by a Postharvest Application of 1-Methylcyclopropene," Postharvest Biology and Technology, Vol. 23, No. 2, 2001 pp. 167-170. doi:10.1016/S0925-5214(01)00099-0

[42] E. D. Mullins, T. G. McCollum and R. E. McDonald, "Consequences on Ethylene Receptor Sites in Disease Non-Climateric Fruit," Postharvest Biology and Technology, Vol. 19, No. 2, 2000, pp. 155-164. doi:10.1016/S0925-5214(00)00077-6

[43] W. Jiang, Q. Sheng, X. J. Zhou, M. J. Zhang and X. J. Liu, "Regulation of Detached Coriander Leaf Senescence by 1-Methylcyclopropene and Ethylene," Postharvest Biology and Technology, Vol. 26, No. 3, 2002, pp. 339-345. doi:10.1016/S0925-5214(02)00068-6

[44] J. B. Golding, D. Shearer, S. G. Wyllie and W. B. McGlasson, "Application of 1-MCP and Propylene to Identify Ethylene-Dependent Ripening Processes in Mature Banana Fruit," Postharvest Biology and Technology, Vol. 14, No. 1, 1998, pp. 87-98. doi:10.1016/S0925-5214(98)00032-5

[45] R. P. Singh, P. V. V. Prasad, K. Sunita, S. N. Giri and K. R. Reddy, "Influence of High Temperature and Breeding for Heat Tolerance in Cotton: A Review," Advances in Agronomy, Vol. 93, 2007, pp. 313-385. doi:10.1016/S0065-2113(06)93006-5 